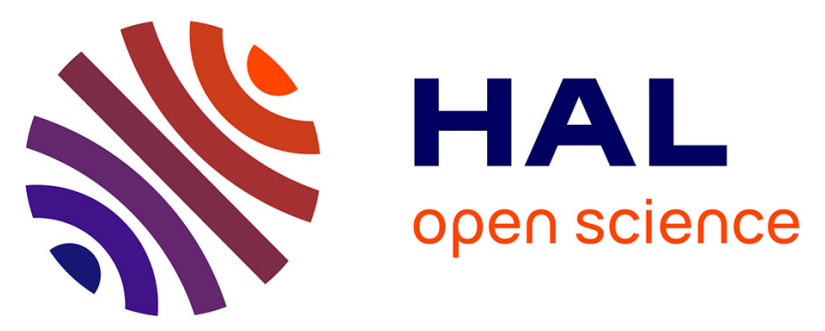

\title{
Laminar Burning Velocities and Kinetic Modeling of a Renewable E-Fuel: Formic Acid and Its Mixtures with $\mathrm{H} 2$ and $\mathrm{CO} 2$
}

S. Mani Mani Sarathy, Pierre Brequigny, Amit Katoch, A. M Elbaz, William L Roberts, Robert W Dibble, Fabrice Foucher

\section{To cite this version:}

S. Mani Mani Sarathy, Pierre Brequigny, Amit Katoch, A. M Elbaz, William L Roberts, et al.. Laminar Burning Velocities and Kinetic Modeling of a Renewable E-Fuel: Formic Acid and Its Mixtures with H2 and CO2. Sustainable Energy \& Fuels, 2020, 34 (6), pp.7564-7572. 10.1021/acs.energyfuels.0c00944 . hal-02934499

\section{HAL Id: hal-02934499 \\ https://hal.science/hal-02934499}

Submitted on 9 Sep 2020

HAL is a multi-disciplinary open access archive for the deposit and dissemination of scientific research documents, whether they are published or not. The documents may come from teaching and research institutions in France or abroad, or from public or private research centers.
L'archive ouverte pluridisciplinaire HAL, est destinée au dépôt et à la diffusion de documents scientifiques de niveau recherche, publiés ou non, émanant des établissements d'enseignement et de recherche français ou étrangers, des laboratoires publics ou privés. 


\section{Laminar burning velocities and kinetic modeling of a renewable e-fuel: formic acid and its mixtures with $\mathrm{H}_{2}$ and $\mathrm{CO}_{2}$}

S. Mani Sarathy ${ }^{1 * \#}$, Pierre Brequigny ${ }^{2 * \#}$, Amit Katoch $^{1}$, A.M. Elbaz ${ }^{1}$, William L. Roberts ${ }^{1}$, Robert W. Dibble $^{1}$, Fabrice Foucher ${ }^{2}$

${ }^{1}$ King Abdullah University of Science and Technology, Clean Combustion Research Center, Physical Sciences and Engineering Division, Thuwal, Kingdom of Saudi Arabia

${ }^{2}$ Univ. Orléans, INSA-CVL, PRISME, EA 4229, F45072, Orléans, France

\# These authors contributed equally to this work.

* Corresponding Authors:

S. Mani Sarathy

E-mail: mani.sarathy@kaust.edu.sa

Pierre Brequigny

E-mail: pierre.brequigny@univ-orleans.fr

Supplementary Materials:

1. Figure showing flame speed vs stretch rate for KAUST experiments.

2. Kinetic model including thermodynamic, mechanism, and transport files. Split into separate files. 


\title{
Laminar burning velocities and kinetic modeling of a renewable e-fuel: formic acid and its mixtures with $\mathrm{H}_{2}$ and $\mathrm{CO}_{2}$
}

S. Mani Sarathy ${ }^{1 * \#}$, Pierre Brequigny ${ }^{2 * \#}$, Amit Katoch ${ }^{1}$, A.M. Elbaz ${ }^{1}$, William L. Roberts ${ }^{1}$, Robert W. Dibble ${ }^{1}$, Fabrice Foucher $^{2}$

${ }^{1}$ King Abdullah University of Science and Technology, Clean Combustion Research Center, Physical Sciences and Engineering Division, Thuwal, Kingdom of Saudi Arabia

${ }^{2}$ Univ. Orléans, INSA-CVL, PRISME, EA 4229, F45072, Orléans, France

\begin{abstract}
Formic acid is a promising fuel candidate that can be generated by reacting renewable hydrogen with carbon dioxide. However, the burning characteristics of formic acid/air mixtures have not been extensively studied. Furthermore, due to its low reactivity, the addition of hydrogen to formic acid/air mixtures may help with improving burning characteristics. This paper presents the first extensive study of formic acid/air premixed laminar burning velocities, as well as mixtures with hydrogen and carbon dioxide. Unstretched laminar burning velocities and Markstein lengths of formic acid in air for two different unburnt gas temperatures and equivalence ratios are presented. Measurements of formic acid mixed with various proportions of hydrogen and carbon dioxide in air are also studied as a potential renewable fuel for the future. Experimental results demonstrate the low burning velocities of formic acid, and the ability to significantly enhance flame speeds by hydrogen addition. A modified detailed kinetic model for combustion of formic acid and its mixtures with hydrogen is proposed by merging wellvalidated literature models. The proposed model reproduces the experimental observations and provided the basis for understanding the combustion kinetics of formic acid laminar premixed flames, as well as mixtures with hydrogen. It is shown that the HOCO radical is the principal intermediate in formic acid combustion, and hydrogen addition accelerates the decomposition of HOCO radical thereby accelerating burning velocities.
\end{abstract}


Keywords: Formic acid, flame speed, chemical kinetic modelling, Marksetin lengths, renewable fuel, hydrogen

\section{Introduction}

Formic acid is widely associated with ants. The "sting" of ants is a sensation caused by formic acid injected into the skin. The injected chemical was first isolated by the distillation of ants. The resulting acidic liquid was called formic acid using the Latin word for ants, "Formica". While insect larvae have been proposed as a source of biofuel [1], we are not suggesting that formic acid is a potential biofuel produced from ants. Formic Acid FA is the simplest carboxylic acid with the structure $\mathrm{HOCHO}$ and $\mathrm{pK}$ of $\sim 4$, much like the pK of its next homolog acetic acid (aka "vinegar"). After its discovery FA was found useful for tanning leathers and then as a bactericide. The current world production of 500,000 tons/year is largely accomplished in Europe.

As an non fossil fuel, hydrogen is widely viewed as an alternative; however, hydrogen is not a liquid and thus demands significant investments in tanks for storage. Because of this storage problem, there is interest in hydrogen-containing molecules, so-called "hydrogen carriers". Ammonia is one example of a hydrogen carrier that can be produced from hydrogen generated using renewable electricity. Such fuels produced from renewable electricity are sometimes called "e-fuels". Methanol is another popular candidate for renewable fuel, is made from $\mathrm{H}_{2}$ and $\mathrm{CO}_{2}$. More recently, FA has been identified as a hydrogen carrier.

Renewable hydrogen can be combined with $\mathrm{CO}_{2}$ to produce the e-fuel, formic acid [2,3]. One liter of formic acid has same amount of compressed hydrogen at 700 bar. FA has been proposed as a hydrogen source for fuel cells, wherein the FA undergoes a simple reaction process to produce pure $\mathrm{H}_{2}$ and $\mathrm{CO}_{2}$ [4]. In this paper, we ask, can formic acid be used as an e-fuel directly in an internal combustion engine? As many combustion systems are designed for combustion of hydrocarbons in air, it is desirable to have flame speeds of new fuels be comparable to flame speeds of hydrocarbons in the air. Methane has a typical flame speed of $S_{l, 0}=43 \mathrm{~cm} / \mathrm{s}$ at atmospheric pressure and $343 \mathrm{~K}$ [5]. On the other hand, formic acid blends 
with oxygen have low burning velocity, as shown by de Wilde and van Tiggelen [6]. The laminar burning velocity of formic acid may be increased by blending with $\mathrm{H}_{2}$, and as noted earlier formic acid can be easily decomposed to $\mathrm{H}_{2}$ and $\mathrm{CO}_{2}$. Therefore, this paper explores the laminar burning velocities of formic acid and its mixtures with $\mathrm{H}_{2}$ and $\mathrm{CO}_{2}$ at various conditions.

There have been limited studies on the combustion of formic acid in flames. Most previous work has dealt with formic acid decomposition in shock tubes and flow reactors [7-11]. The most recent theoretical work on formic acid was performed by Marshall and Glarborg [12], and they also summarized all previous literature on this fuel. The authors performed high-level quantum chemical thermochemistry and kinetic calculations to identify critical formic acid consumption pathways. In addition, they developed a chemical kinetic model that was validated against flame speed measurements performed by de Wilde and van Tiggelen [6]. Given then aforementioned interest in formic acid as an e-fuel, we conducted a detailed investigation of its laminar burning velocities at various initial temperatures and equivalence ratios. To promote the viability of using formic acid in real engines, we also studied laminar premixed flames of formic acid blended with various proportions of $\mathrm{H}_{2}$ and $\mathrm{CO}_{2}$. To provide further insights into the combustion of formic acid and its mixtures with $\mathrm{H}_{2}$, we also present an updated chemical kinetic model and use it to perform flux and sensitivity analyses.

\section{Experimental and Computational Methods}

\section{Experimental Setup}

The experiments were performed in a spherical stainless steel combustion chamber, as reported in $[13,14]$. Since both setups (PRISME and KAUST) follow similar methodology, for the sake of conciseness, only the configuration and methodology of PRISME vessel is discussed. The inner volume of the chamber is 4.2 L with an inner diameter of $200 \mathrm{~mm}$. The outer surface of the sphere is equipped with a heater wire resistance to heat the fresh gases to a maximum initial temperature of $473 \mathrm{~K}$. Experiments were carried out at initial pressure of 0.1 MPa. Equivalence ratios were calculated considering the following reaction: 
$\mathrm{HOCHO}+0.5\left(\mathrm{O}_{2}+3.78 \mathrm{~N}_{2}\right)=\mathrm{CO}_{2}+\mathrm{H}_{2} \mathrm{O}+1.89 \mathrm{~N}_{2}$. Equivalence ratio influence was investigated in the range $0.8-1.3$. Moreover, in order to simulate a pre-decomposition of formic acid into hydrogen and carbon dioxide, the following blends were tested and considered as fuel in the same range of equivalence ratio: $25 \% \mathrm{HOCHO} / 37.5 \% \mathrm{H}_{2} / 37.5 \% \mathrm{CO}_{2} ; 30 \% \mathrm{HOCHO} / 35 \% \mathrm{H}_{2} / 35 \% \mathrm{CO}_{2}$; and $35 \% \mathrm{HOCHO} /$ $32.5 \% \mathrm{H}_{2} / 32.5 \% \mathrm{CO}_{2}$.

Before filling the sphere with gases, a vacuum pump was used to evacuate the combustion chamber and reach a pressure $<0.009$ bar. Formic acid on one hand and air, hydrogen and carbon dioxide, on the other hand, were injected by a Coriolis mass flow meter and thermal flow meters, respectively. In this experiment, air was directed to the exit of the Coriolis mass flowmeter to convey the liquid formic acid. The composition of the synthetic air used was $79.1 \% \mathrm{~N}_{2}$ and $20.9 \% \mathrm{O}_{2}$. Before being introduced in the sphere, the inlet valve heated the mixture to $373 \mathrm{~K}$ to fully vaporize the acid. The sphere walls were also heated up to $373 \mathrm{~K}$ to avoid condensation. Since formic acid is injected in vacuum conditions and the final partial pressure is well below atmospheric pressure, condensation is not an issue. We confirmed there is no condensation or decomposition of FA by measuring its mole fraction using gas chromatography mass spectometry. The sphere is equipped with a fan to obtain a perfectly homogeneous mixture. The fan was stopped $10 \mathrm{~s}$ before the ignition to prevent any perturbation that could disturb the flame propagation. The maximum deviation between the effective initial pressure inside the combustion chamber and the required initial pressure was about $0.5 \%$. The temperature fluctuation of the prepared mixture was within $2 \mathrm{~K}$ from the desired initial temperature. Two tungsten electrodes ( $1 \mathrm{~mm}$ diameter), with a $1 \mathrm{~mm}$ gap, linked to a conventional capacitive discharge ignition system were used. In the present experiments, the time charge of the ignition coil was set to $3 \mathrm{~ms}$ which corresponds to the discharge energy of less than $100 \mathrm{~mJ}$. More details can be found concerning the device in [15].

To measure laminar flame speeds, the Schlieren technique was used. Optical access into the chamber was provided by two opposite and transparent windows (diameter $70 \mathrm{~mm}$ ). A white LED lamp was used to provide continuous and incoherent light. A parallel light was obtained using a pinhole (diameter $0.8 \mathrm{~mm}$ ), 
placed just in front of the LED. The optical setup is fully described in Fig.1 Instantaneous images were recorded using a Phantom v1210 high-speed video camera operating at 10000 images per second. The temporal evolution of the expanding spherical flame was then processed. Images of $640 \times 800$ pixels $^{2}$ were recorded with a magnification ratio of $0.11 \mathrm{~mm} /$ pixel. Measurements are limited to flames with a diameter greater than $6.5 \mathrm{~mm}$ to avoid ignition effect and lower than 25 For the extrapolation, the minimium flame radius considered to avoid ignition effect was $6.5 \mathrm{~mm}$, as suggested by Bradley et al. [16], and validated on PRISME setup in [17]. The maximum radius used was $25 \mathrm{~mm}$ when possible. This radius corresponds to less than $1.6 \%$ of the volume of the vessel which avoids pressure increase (isobaric hypothesis) and confinement effects [18]. In some cases, when cells on the flame surface appeared, this maximum radius was adapted from one case to another and decreased to before the onset of cellularities. From image post-processing, the temporal flame front radius evolution was obtained. Images were processed using an in-house routine after background subtraction. The stretch rate for a spherical flame is given as $\kappa=\left(\frac{2}{R_{f}}\right) S_{n}$ where $S_{n}=\frac{d R_{f}}{d t}$ is the stretched flame propagation speed and $R_{f}$ represents the mean flame radius, obtained from Schlieren measurement of the projected flame area. Since the flames are stretched, correlations are employed to evaluate the unstretched laminar flame speed by extrapolation to zero stretch. The KAUST vessel employs linear extrapolation, $S_{0}-S_{n}=L_{b} \kappa$, where $L_{b}$ is the Markstein length of the burnt gas, $S_{0}$ the unstreched flame speed, $S_{n}$ is the stretched flame speed, and $\kappa$ is the stretch rate. Both linear and non-linear extrapolations give very similar results when the Markstein length is close to zero and there is a large monotonous speed vs. stretch curve, as shown in Figure S1 in the Supplementary Material The PRISME vessel employs non-linear correlations proposed by Kelly and Law [19] and Halter et al. [20]: $\left(\frac{S_{n}}{S_{0}}\right)^{2} \ln \left(\frac{S_{n}}{S_{0}}\right)^{2}=-\frac{2 L_{b} \kappa}{S_{0}}$.

Using the expansion factor, the unstretched laminar burning velocity $S_{l, 0}$ is calculated as: $S_{l, 0}=S_{0}\left(\frac{\rho_{b}}{\rho_{u}}\right)$ where $\rho_{b}$ and $\rho_{u}$ are the burned gas density and unburned mixture density, respectively, which were 
calculated from EQUIL [21] subroutine of CHEMKIN-PRO. For each condition, 3 to 4 tests were carried out in order to obtain averaged values and standard deviation. Results are presented with error bars which represent uncertainties obtained considering errors on the radius estimation, deviation on the initial pressure and temperature, a statistical error with a 95\% confidence calculated from the Student's law and the standard deviation, as well as radiation induced error as described in [22]. Yu et al. [23] showed the impact of radiative heat losses on LBV measurement could be of importance when LBV is lower than 20 $\mathrm{cm} / \mathrm{s}$. Lhuillier et al. [22] recently showed that for ammonia/air mixtures, the error could reach up to $50 \%$ for very low LBV and $5 \%$ for LBV about $10 \mathrm{~cm} / \mathrm{s}$. For hydrocarbon fuels, the error seems to be higher according to work of Yu et al [23]. The correlation of Yu et al. was therefore applied to estimate the error on the current PRISME data. For the lowest LBV value, i.e $17.4 \mathrm{~cm} / \mathrm{s}$ for pure $\mathrm{HOCHO} /$ air blend at $373 \mathrm{~K}$ and $\phi=0.785$, the radiation induced error obtained is about $7.5 \%$ and goes down to about $2.6 \%$ in the best case for higher LBV. Details radiation induced error in the KAUST vessel can be found in [14], wherein iso-octane flame speed measurements [2] showed that radiation related uncertainty was $4 \%$ for the lowest measured flame speeds $(14-15 \mathrm{~cm} / \mathrm{s}$ at phi=1.5). In the present work, the lowest flame speeds for formic $\mathrm{acid} / \mathrm{H}_{2}$ mixtures measured at KAUST is $\sim 14 \mathrm{~cm} / \mathrm{s}$. These errors were taken into account into the uncertainy calculation and added on the positive side of the uncertainty bar in the LBV results.

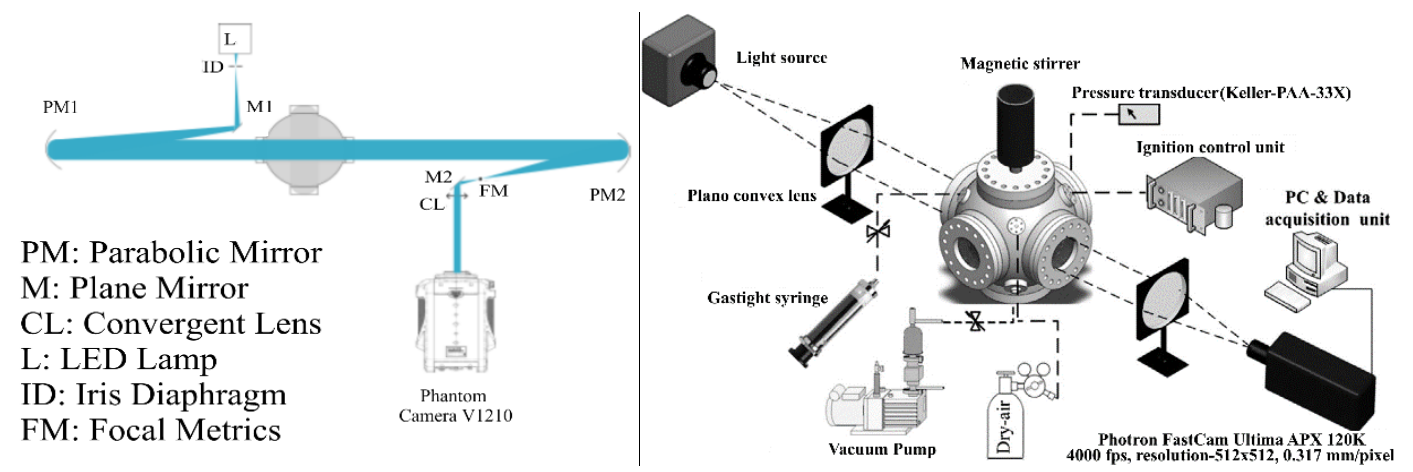

Figure 1 - Schematic overview of the experimental setup used at PRISME, Univ. Orleans (left) and KAUST (right).

\section{Chemical Kinetic Modeling}


Detailed chemical kinetic modelling was performed to predict the laminar burning velocity of HOCHO and its mixtures with $\mathrm{H}_{2}$, and $\mathrm{CO}_{2}$. The present work utilized AramcoMech 2.0 [24-28] as the base mechanism due to its widely validated chemistry for $\mathrm{H}_{2}, \mathrm{CO}$, and $\mathrm{C}_{1}-\mathrm{C}_{3}$ hydrocarbons. The formic acid sub-mechanism in AramcoMech 2.0 has not been rigorously developed or validated, and we found that it does not accurately reproduce the laminar burning velocity data obtained herein. To our knowledge, the most detailed kinetic study performed on formic acid is executed by Marshall and Glarborg [12]. They conducted a detailed theoretical study on various HOCHO oxidation pathways and provided improved thermodynamic properties and kinetic parameters. As shown later, the mechanism proposed by Marshall and Glarborg slightly over predicts formic acid/air burning velocities obtained here. Therefore, we updated AramcoMech 2.0 with the HOCHO sub-mechanism from Marshall and Glarborg [12]. Thermodynamic data for $\mathrm{HOCHO}$ and its radical intermediates, $\mathrm{HOCO}$ and $\mathrm{OCHO}$ were adopted from the sources $[29,30]$ recommended by Marshall and Glarborg [12]. Their formic acid reaction sub-mechanism and associated kinetic parameters were adopted without modification. The relevant reactions replaced in AramcoMech 2.0 are associated with formic acid unimolecular decomposition, H-atom abstraction from HOCHO, and the decomposition of its radical intermediates ( $\mathrm{HOCO}$ and $\mathrm{OCHO}$ ). The kinetic model is available as Supplementary Material. All simulations were conducted in ANSYS CHEMKIN PRO using the PREMIX module. Thermal diffusion was included with average mixture transport. Gradient (GRAD) and curvature (CURV) were set at 0.05 to ensure highly resolved flame structures, and solutions were converged at above 200 grid points.

\section{Results and Discussion}

Experimental results for the laminar burning velocity (LBV) of HOCHO/air mixture are presented as a function of equivalence ratio for two initial temperatures: 373 and $423 \mathrm{~K}$ in Fig. 2 (left panel). Results show a maximum laminar burning velocity for slightly rich mixtures between $\phi=1.1$ and $\phi=1.2$ comparable with conventional hydrocarbon fuels. The LBV values are quite low compared to 
conventional hydrocarbons. For instance, stoichiometric methane/air at 1 bar, 373K displays a LBV of $0.53 \mathrm{~m} / \mathrm{s}$ using AramcoMech 2.0. The experimental results are also compared with the Marshall and Glarborg model [12]. The experimental results show good agreement with the mechanism especially at $423 \mathrm{~K}$. The mechanism of Marshall and Glarborg was validated using the data of de Wilde and van Tiggelen [6]. Those data were not obtained at $433 \mathrm{~K}$ and with air as oxidizer but with high oxygen content ( $\min 76 \%$ vol. $\mathrm{O}_{2}$ ) leading to higher values: between 65 and $85 \mathrm{~cm} / \mathrm{s}$ for the conditions investigated in [6]. A higher discrepancy is observed between the Marshall and Glarborg mechanism and the present experiments at $373 \mathrm{~K}$, up to $5 \mathrm{~cm} / \mathrm{s}$ in the worst case.

At $423 \mathrm{~K}$, the model developed in this work reproduces the present experimental measurements within the uncertainty bounds at all conditions except the richest equivalence ratio, at which point the model is within $10 \%$ of the experimental measurement. The position of maximum burning velocity at $423 \mathrm{~K}$ in both experiments and simulations is between $\phi=1.1$ and $\phi=1.2$. At $373 \mathrm{~K}$, the proposed model reproduces the experimental measurements at lean conditions; however, at stoichiometric and rich conditions, the model shows up to $15 \%$ discrepancy with the experimental measurements (less if the error bars are considered). The position of maximum burning velocity at $373 \mathrm{~K}$ is difficult to ascertain from the measurements given the uncertainties; however, both experiments and simulations show a relatively small variation in burning velocity (within $1 \mathrm{~cm} / \mathrm{s}$ ) from $\phi=1$ to $\phi=1.3$.

Fig. 2 also compares the present model against measurements by de Wilde and van Tiggelen [6] obtained in high $\mathrm{O}_{2}$ content mixtures with $\mathrm{N}_{2}$. The present model accurately reproduces the location of peak LBV (near $\phi=0.8$ ) at all conditions, as well as measurements with $12 \% \mathrm{~N}_{2}$ dilution. However, the model over predicts data acquired under high $\mathrm{N}_{2}$ dilutions. Similar levels of agreement were observed by Marshall and Glarborg using their model [1]. Given that the measurements by de Wilde and van Tiggelen [6] were acquired prior to many modern developments in LBV measurements, we did not tune the model to match those experiments. 

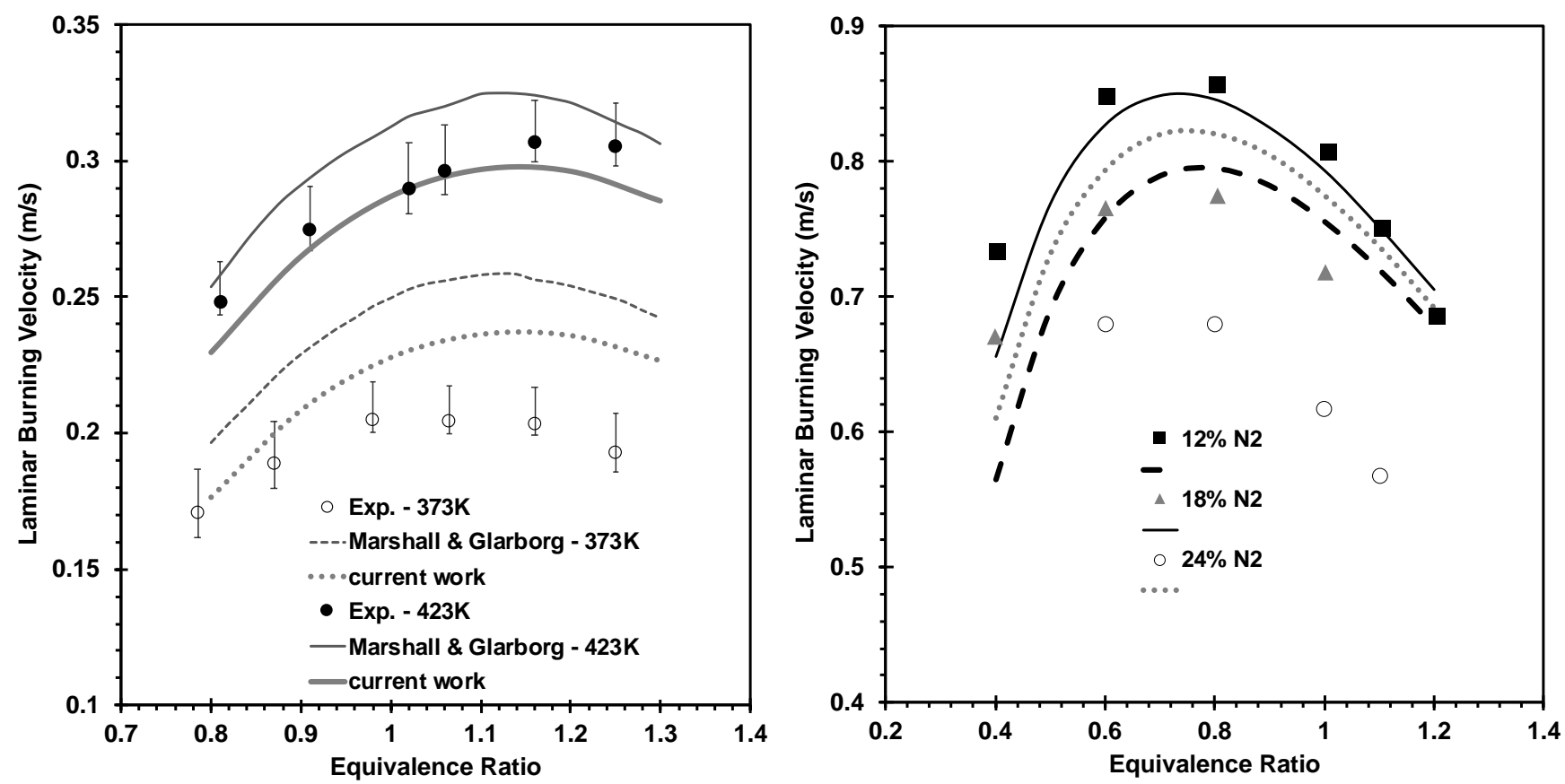

Figure 2 - (left) LBV versus equivalence ratio for HOCHO/Air blend at 1 bar for two initial temperatures 373K and $423 \mathrm{~K}$. Experimental data (symbols) from and simulations with present model and that from Marshall and Glarborg [12]. (right) Comparison of the present model with data for $\mathrm{HOCHO} / \mathrm{O}_{2} / \mathrm{N}_{2}$ at $433 \mathrm{~K}$ and various levels of $\mathrm{N}_{2}$ dilution. Experimental data from de Wilde and van Tiggelen [6] simulations (lines) with present model.

Considering formic acid as a potential fuel, its low LBV is a drawback for premixed combustion application such as gas turbines or spark-ignition engines. As it is currently done with other low reactivity fuels, such as ammonia [31,32], another fuel such as hydrogen or methane could be used as a reactivity promoter. Formic acid can be produced from $\mathrm{H}_{2}$ and $\mathrm{CO}_{2}$ with a maximum efficiency of $42 \%$ currently [33], and formic acid can be catalytically decomposed back to $\mathrm{H}_{2}$ and $\mathrm{CO}_{2}$. Therefore, it is interesting to 
study $\mathrm{H}_{2} / \mathrm{CO}_{2} / \mathrm{HOCHO}$ blend as potential candidate for premixed combustion. The following blends were tested and considered as fuels: $25 \% \mathrm{HOCHO} / 37.5 \% \mathrm{H}_{2} / 37.5 \% \mathrm{CO}_{2} ; 30 \% \mathrm{HOCHO} / 35 \% \mathrm{H}_{2} / 35 \%$ $\mathrm{CO}_{2}$; and $35 \% \mathrm{HOCHO} / 32.5 \% \mathrm{H}_{2} / 32.5 \% \mathrm{CO}_{2}$. The ratios were selected from the first round of simulations to obtain LBV values similar to methane/air mixtures. Moreover, considering these blends as potential fuel for spark-ignition engines, unburned formic acid at the exhaust is unacceptable. Therefore, the experiments at PRISME focused on lean equivalence ratios ranging from 0.5 to 0.9 to obtain maximum combustion efficiency and to be in a low NOx region for future applications. For comparisons, experiments at KAUST have conducted for 10\% $\mathrm{H} 2 / 90 \% \mathrm{HOCHO}$ mixture as the fuel at $358 \mathrm{~K}$ and lean to rich conditions Fig. 3 presents LBV obtained from experiments and simulations with proposed model for the studied blends.

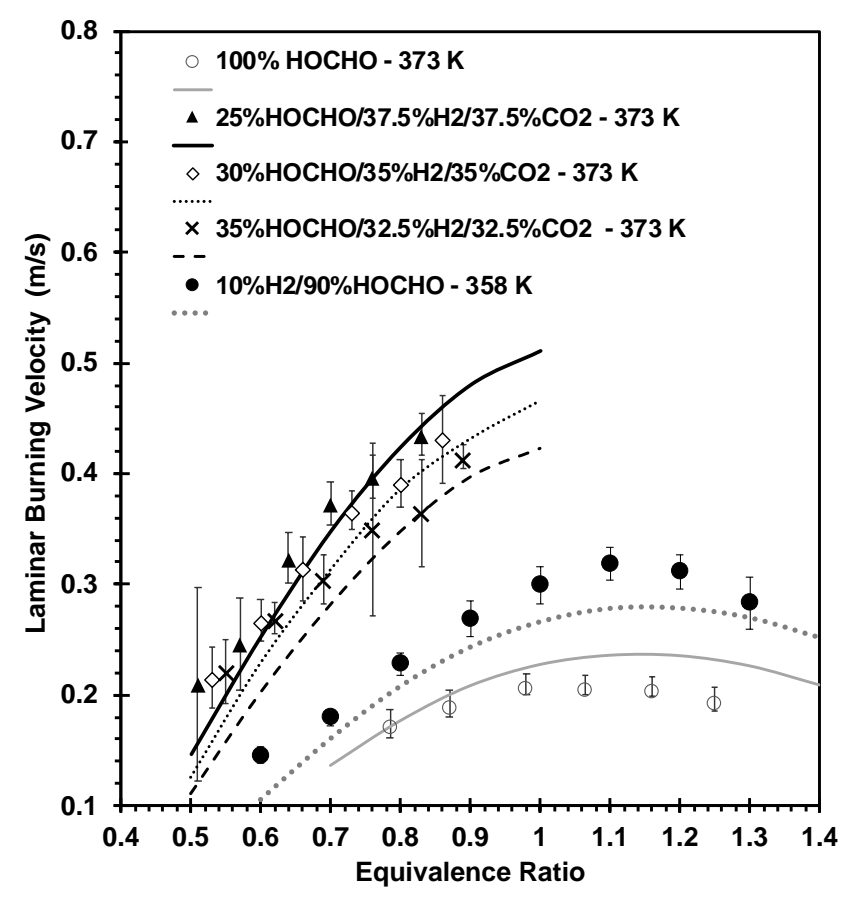

Figure 3. LBV vs. equivalence ratio at 1 bar and $373 \mathrm{~K}$ for various $\mathrm{HOCHO} / \mathrm{H}_{2} / \mathrm{CO}_{2} /$ air blends and $358 \mathrm{~K}$ for $10 \% \mathrm{H}_{2} / 90 \% \mathrm{HOCHO} /$ air blend. Symbols are experimental data and lines are simulations using the present model.

Fig 3. shows that mixing $90 \% \mathrm{HOCHO}$ with $10 \% \mathrm{H}_{2}$ and burning in air increases the LBV compared to pure $\mathrm{HOCHO}$, even though the former were performed at lower unburnt gas temperatures. The proposed kinetic model is able to predict the effect of $\mathrm{H}_{2}$ blending on LBV. Comparisons against predictions made 
by the Marshall and Glarborg [12] model are shown in the Supplementary Material Figure S2. Furthermore, blending $\mathrm{H}_{2}$ and $\mathrm{CO}_{2}$, which are the complete decomposition products of $\mathrm{HOCHO}$, can extend the flammability toward leaner mixtures. In addition, it enables an increase in the LBV to $\sim 40 \mathrm{~cm} / \mathrm{s}$ at $\mathrm{ER}=0.9$ which is comparable to $\mathrm{CH} 4$ /air $\mathrm{LBV}$ at similar conditions. $\mathrm{LBV}$ displays similar values for very lean mixtures regardless of hydrogen content, which can be explained by measurement difficulties in lean flammability limit region. The proposed mechanism well predicts the LBV of 90\% $\mathrm{HOCHO} / 10 \%$ $\mathrm{H}_{2}$ and all $\mathrm{HOCHO} / \mathrm{H}_{2} / \mathrm{CO}_{2}$ blends compared to the present experimental work. Moreover, the differences in the three $\mathrm{HOCHO} / \mathrm{H}_{2} / \mathrm{CO}_{2}$ blends obtained with the mechanism are in good agreement with the experiments, i.e., increase the $\mathrm{H}_{2}$ content increases LBV. Finally, the shift of the maximum LBV towards rich equivalence ratio that is observed when blending $10 \%$ hydrogen with $90 \%$ HOCHO is also observed in simulations with the proposed mechanism.

The standard deviations are the high for the $35 \% \mathrm{HOCHO}$ blend at $\phi=0.76$ and 0.83 because only two successful measurements could be obtained. For those cases, one of the experimental runs showed cellularity early in the flame development, thus preventing the images from being processed. The same happened for the $25 \% \mathrm{HOCHO}$ blend at $\phi=0.51$ where higher uncertainty is observed. As a result, having only two valid measurements of LBV and $L_{b}$ for such conditions leads to a high statistical error because the Student's Law result increases with the decreasing number of tests. Moreover, highly negative Markstein length cause thermodiffusive instabilities, and therefore cellularity on the flame surface at some point. To avoid those cells, the radius range usable for the extrapolation is sometimes reduced, which adds to the challenge of finding a fit under such conditions.

Since flame stretch can have a significant impact on early flame kernel development and therefore combustion phasing in SI engines [35], it is worth measuring the Markstein length to have an idea of the flame response to stretch and its impact on turbulent flame propagation in engines. It is especially important when introducing $\mathrm{H}_{2}$ since its use implies a significant change in Markstein length and Lewis number based thermodiffusive instabilities at lean equivalence ratios. Fig.4 presents the Markstein lengths 
obtained from Eq. 1 at 1 bar and $373 \mathrm{~K}$ for all the studied blends at PRISME and the $10 \% \mathrm{H}_{2}$ blend tested at KAUST. The error bars presented in Fig. 4 only account for standard deviation unlike previous figures.

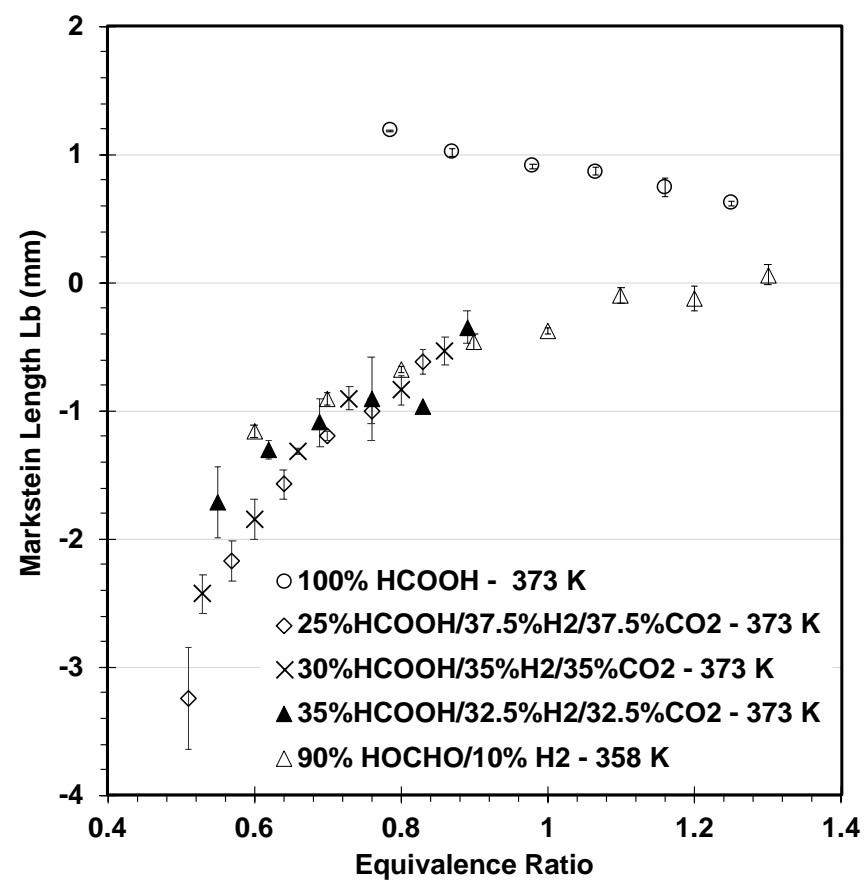

Figure 4. Markstein length versus equivalence ratio at $1 \mathrm{bar}, 373 \mathrm{~K}$ for all the $\mathrm{HOCHO} / \mathrm{H}_{2} / \mathrm{CO}_{2} / \mathrm{air} \mathrm{blends}$ and $358 \mathrm{~K}$ for $10 \% \mathrm{H}_{2} / 90 \% \mathrm{HOCHO/air} \mathrm{blend.}$

Markstein lengths are about $1 \mathrm{~mm}$ for $\mathrm{HOCHO} /$ Air mixture with a typical decrease as equivalence ratio increases. This is similar in terms of absolute values and trend to conventional fossil fuels such as isooctane, as shown in [15]. High positive values of Markstein length leads to a decrease in flame speed when flame stretch increases, thus making the early flame kernel propagation slow, i.e. when stretch levels are high. This is moreover representative of a stable flame without any cellularity occurring during the propagation under laminar conditions. Adding $\mathrm{H}_{2}$ to the blend completely changes that behaviour and leads to negative Markstein lengths. Negative Markstein lengths cause a decrease in flame speed as the flame propagates. The flame speed is then at its highest value in early flame kernel development when stretch levels are high, which can be beneficial in the moments right after the spark ignition. The negative Markstein length is also representative of unstable flames with cells appearing on the flame surface during 
laminar propagation due to thermodiffusive instabilities, as Lewis number is low. Those instabilities make LBV measurements more difficult and lead to higher standard deviations. Finally, when adding hydrogen, the evolution of Markstein length as a function of equivalence ratio changes: for $\mathrm{HOCHO} / \mathrm{H}_{2} / \mathrm{CO}_{2}$ and $\mathrm{H}_{2} / \mathrm{HOCHO}$ blends, it is opposite to pure HOCHO. Indeed, increasing the equivalence ratio increases the Markstein length for the $\mathrm{HOCHO} / \mathrm{H}_{2} / \mathrm{CO}_{2}$ and $\mathrm{H}_{2} / \mathrm{HOCHO}$ blends making the flame more stable contrary to pure HOCHO. This is a typical behaviour of hydrogen, which reacts to flame stretch oppositely to conventional fuels, such as isooctane. In the range of equivalence ratios studied, the Markstein lengths remain negative, but the trend suggests that values will become positive for stoichiometric and rich blends. The change of Markstein length with hydrogen addition was already shown by Bradley et al. with methane [36], especially for lean mixtures where Lewis number and Markstein length for hydrogen are low. Bradley et al. showed that adding hydrogen to methane decreases the Markstein length almost linearly, but $\mathrm{L}_{b}$ remains positive from $\mathrm{ER}=1.0$ to 1.2 regardless of $\mathrm{H}_{2}$ content consistently with the work of Tahtouh et al. for stoichiometric methane-air [37] or stoichiometric isooctane-air [38]. Bradley et al. also showed that for $\mathrm{CH}_{4} / \mathrm{H}_{2}$ blends, increasing the equivalence ratio leads to an increase of the Markstein length similarly to observed here in Fig. 4. Hence, the stretch dependence of the $\mathrm{HOCHO} / \mathrm{H}_{2} / \mathrm{CO}_{2}$ blend seems to be mainly dominated by the hydrogen response to stretch.

Another source of uncertainty in Markstein length and LBV measurement is the extrapolation used. Wu et al [34] showed that, to have a negligible uncertainty due to the extrapolation, the ratio $2 L_{b, l i n} / R_{f, \text { mid }}$ should lie between -0.1 and $0.15 . L_{b, l i n}$ is the Markstein length obtain with the linear extrapolation and $R_{f, \text { mid }}$ is the middle radius of the data used. There are two ways to limit the extrapolation: (i) either have a zero Markstein length blend, i.e Lewis number close to unity, or (ii) have a large range of radius usable for the processing. Since the current blends are chosen as is, only the second condition can be modified by increasing the minimum radius use for the extrapolation, but it is still a moderate change with a quite small vessel such as the PRISME one. For the KAUST vessel, the vessel is sufficiently large such that linear and non-linear extrapolation provide neglible differences (see Figure S1). For the extreme 
Markstein length values, i.e $1.2 \mathrm{~mm}$ and $-3.4 \mathrm{~mm}$ for pure $\mathrm{HOCHO}$ at $\phi=0.8$ and $25 \% \mathrm{HOCHO}$ at $\phi=$ 0.51, respectively, the extrapolation plots are presented in Fig. 5 for the PRISME experiments.
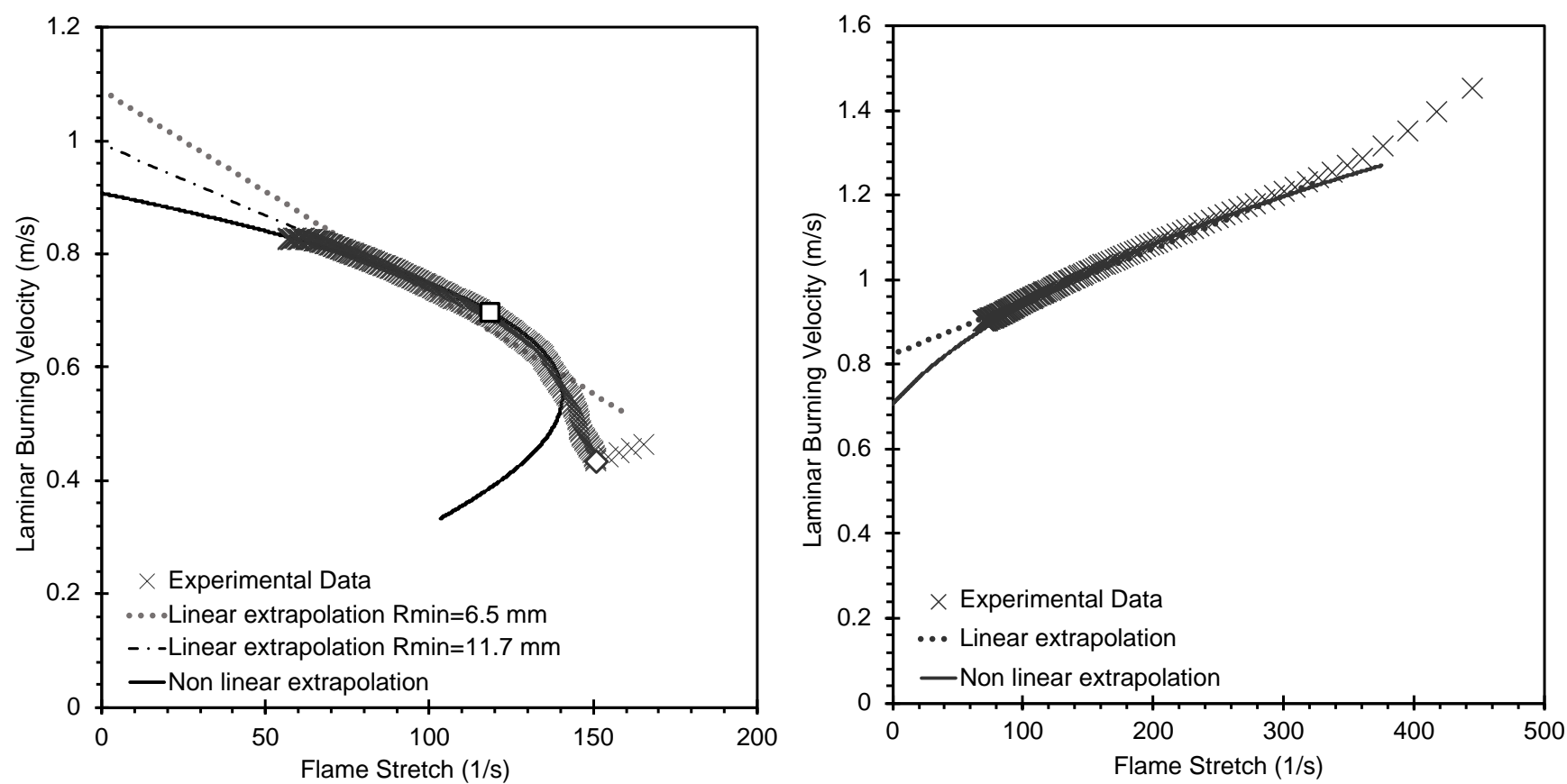

Figure 5. Flame speed extrapolations as function of stretch for the extreme Markstein length values. Left: pure HOCHO at $\phi=0.8$; Right: $25 \%$ HOCHO blend at $\phi=0.51$.

For the positive Markstein length value, with the full radius range, i.e 6.5 to $25 \mathrm{~mm}$, the non-linear extrapolation appears to better fit the data. The Markstein length obtained with the linear extrapolation is about $3.56 \mathrm{~mm}$ leading to a value of 0.45 for the criterion of Wu et al., which is too high. To have a better fit of the data with the linear extrapolation, the minimum radius was increased up to $11.7 \mathrm{~mm}$ leading to values of $2.5 \mathrm{~mm}$ and 0.27 for the Markstein length and Wu's criterion, respectively. The change in the unstreched flame speed obtained with the linear extrapolation when changing the minimum radius is about 9\% (from 1.08 to $0.99 \mathrm{~m} / \mathrm{s}$ ). The non-linear extrapolation is much less sensitive to the radius range. According to the work of Wu et al. with $\mathrm{H}_{2}$, for $2 L_{b, l i n} / R_{f, \text { mid }}=0.27$, the linear extrapolation leads to an underprediction of about $5 \%$ on the unstretched flame speed whereas it is about $10 \%$ with the non-linear extrapolation. For the negative Markstein length value, i.e $-3.4 \mathrm{~mm}$ and $-1.25 \mathrm{~mm}$, with the non-linear and 
linear extrapolation, respectively, the criterion is equal to $-0.17\left(7.5 \mathrm{~mm}<R_{f}<22 \mathrm{~mm}\right)$. However a $17 \%$ difference can be observed on the unstreched flame speed values between the two correlations. In this case, the non-linear one is preferred since the linear overpredicts the unstreched flame speed according to the paper of $\mathrm{Wu}$ et al.. In any case, it can be seen that the criterion suggested by $\mathrm{Wu}$ et al. to limit the extrapolation error is obtained for $L_{b}$ between -0.3 and $1 \mathrm{~mm}$, which is valid for most our data for pure $\mathrm{HOCHO}$ and for the stoichiometric to rich $\mathrm{HOCHO} / \mathrm{H}_{2}$ blends, but cannot be reached for the $\mathrm{HOCHO} / \mathrm{H} 2 / \mathrm{CO} 2$ blend. In those cases, the non-linear extrapolation is preferred since the error will be less than with the linear extrapolation thus justifying the use of this model. Nonetheless, this can still results in a $25 \%$ overprediction of the unstreched flame speed according to Wu et al.. An improvement for the current data could be to used the non-linear model with 3 fitting parameters proposed by Wu et al. as follows $\frac{S_{n}}{S_{0}}=1-\frac{2 L_{b}}{R_{f}}+\frac{C}{R_{f}^{2}}$ with $\mathrm{C}$ a constant to be determined.

Reaction path flux was conducted for $\mathrm{HOCHO} /$ air and 25\% $\mathrm{HOCHO} / 37.5 \% \mathrm{H} 2$ / 37.5\% CO2 / air mixtures at 1 bar, $373 \mathrm{~K}$, and stoichiometric conditions. Figure 5 shows the consumption of HOCHO and its intermediates at a flame position corresponding to $75 \%$ of the $\mathrm{HOCHO}$ consumed. This corresponds to a temperature of $\sim 1250 \mathrm{~K}$ in the HOCHO/air flame and $1380 \mathrm{~K} 25 \% \mathrm{HOCHO} / 37.5 \% \mathrm{H} 2 / 37.5 \%$ $\mathrm{CO} 2 /$ air. In both flames, $\mathrm{HOCHO}$ is mainly consumed via $\mathrm{H}$-atom abstraction by $\mathrm{OH}, \mathrm{H}$, and $\mathrm{O}$ radicals. $\mathrm{H}$-abstraction from the $\mathrm{C}$ atom is the dominant route leading to $\mathrm{HOCO}$ radical. A small percentage of $\mathrm{HOCHO}$ is consumed to form OCHO radical, which rapidly and exclusively decomposes to form $\mathrm{CO}_{2}+$ $\mathrm{H}$. The HOCO radical, being the predominant intermediate, is consumed differently in the pure HOCHO and $\mathrm{H} 2$ blended flames. In the pure $\mathrm{HOCHO}$ flame, $\mathrm{HOCO}$ mainly decomposes via $\mathrm{OH}$ loss to produce $\mathrm{CO}$, which subsequently reacts with $\mathrm{OH}$ radicals to produce $\mathrm{CO}_{2}+\mathrm{H}$. The same reaction is important in $\mathrm{H}_{2}$ blended flames, albeit $\mathrm{HOCO}$ also reacts more with $\mathrm{H}$ radicals to produce $\mathrm{CO}$ and $\mathrm{H}_{2} \mathrm{O}$. In the pure HOCHO flame, $\mathrm{HOCO}$ also reacts with $\mathrm{O}_{2}$ to produce $\mathrm{CO}_{2}+\mathrm{HO}_{2}$ directly, but this reaction is less important in the $\mathrm{H}_{2}$ blended flame. In summary, the primary difference in the two flames appears to be 
on the role of $\mathrm{H}$ atoms in the $\mathrm{H} 2$ blended flame in producing more $\mathrm{CO}$. Increasing $\mathrm{CO}$ concentrations then contribute to higher flame speeds due to the largely exothermic $\mathrm{CO}+\mathrm{OH}=\mathrm{CO}_{2}+\mathrm{H}$ reaction.

To better understand the role of specific reactions and species heat of formation, a sensitivity analysis was conducted for $\mathrm{HOCHO} /$ air mixtures at $373 \mathrm{~K}, 1$ bar, stoichiometric conditions, and position corresponding to $75 \%$ of the fuel consumed, as shown in Figure 6. A positive sensitivity coefficient indicates that increasing the A-factor or heat of formation will increase concentration of the corresponding species. The reaction sensitivity analysis in Fig. 6 shows that HOCHO concentration has a strong negativity sensitivity to $\mathrm{HOCO}$ decomposition to $\mathrm{CO}$ and $\mathrm{OH}$; concentrations $\mathrm{H}$ and $\mathrm{OH}$ radicals, which are the key radicals in premixed flame propagation, show a strong positive sensitivity to this reaction. An opposite trend is displayed for the reaction of $\mathrm{HOCO}+\mathrm{O}_{2}=\mathrm{CO}_{2}+\mathrm{HO}_{2}$, since it competes directly with the aforementioned HOCO decomposition reaction. Species concentrations are also strongly sensitivity to the heat of formation of HOCO, as shown in Fig. 6. In microkinetic modeling, heats of formation $\left(\mathrm{H}_{\mathrm{f}}\right)$ are important for determining the reverse rate constant $\left(\mathrm{k}_{\mathrm{r}}\right)$ from the forward rate constant $\left(\mathrm{k}_{\mathrm{f}}\right)$, equilibrium constant $(\mathrm{K})$, and the Gibbs free energy $\left(\Delta \mathrm{G}_{\mathrm{rxn}}=-\mathrm{RT} \ln \mathrm{K} ; \Delta \mathrm{G}_{\mathrm{rxn}}=\Delta \mathrm{H}_{\mathrm{rxn}}-\mathrm{T} \Delta \mathrm{S}_{\mathrm{rxn}}\right)$; where $\mathrm{R}$ is the gas constant, $\mathrm{T}$ is

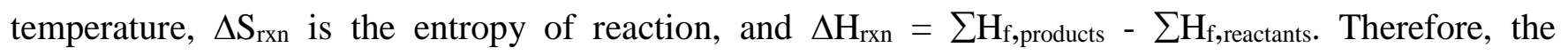
formation/destruction of the fuel and important intermediates (as well as the flame speed) is sensitive to both forward reaction rates, indicated by the reaction rate sensitivity analysis, and heat of formation sensitivity (via the reverse reaction rate). The sensitivity analysis also shows that heats of formation $\mathrm{CO}_{2}$, $\mathrm{CO}, \mathrm{H}, \mathrm{OH}$, and $\mathrm{HOCHO}$ are important in controlling the concentrations of fuel and important intermediate radicals. The heats of formation for $\mathrm{CO}_{2}, \mathrm{CO}, \mathrm{H}, \mathrm{OH}$, and $\mathrm{HOCHO}$ are well defined. However, those of HOCO and OCHO have larger uncertainties and should be the focus of more refined theoretical and experimental studies. The HOCO heat of formation is more important in determining $\mathrm{H}$ and $\mathrm{OH}$ radical concentrations and flame speed because, as shown in the flux analysis, HOCHO is primarily consumed to form $\mathrm{HOCO}$, while OCHO is the less important intermediate. 


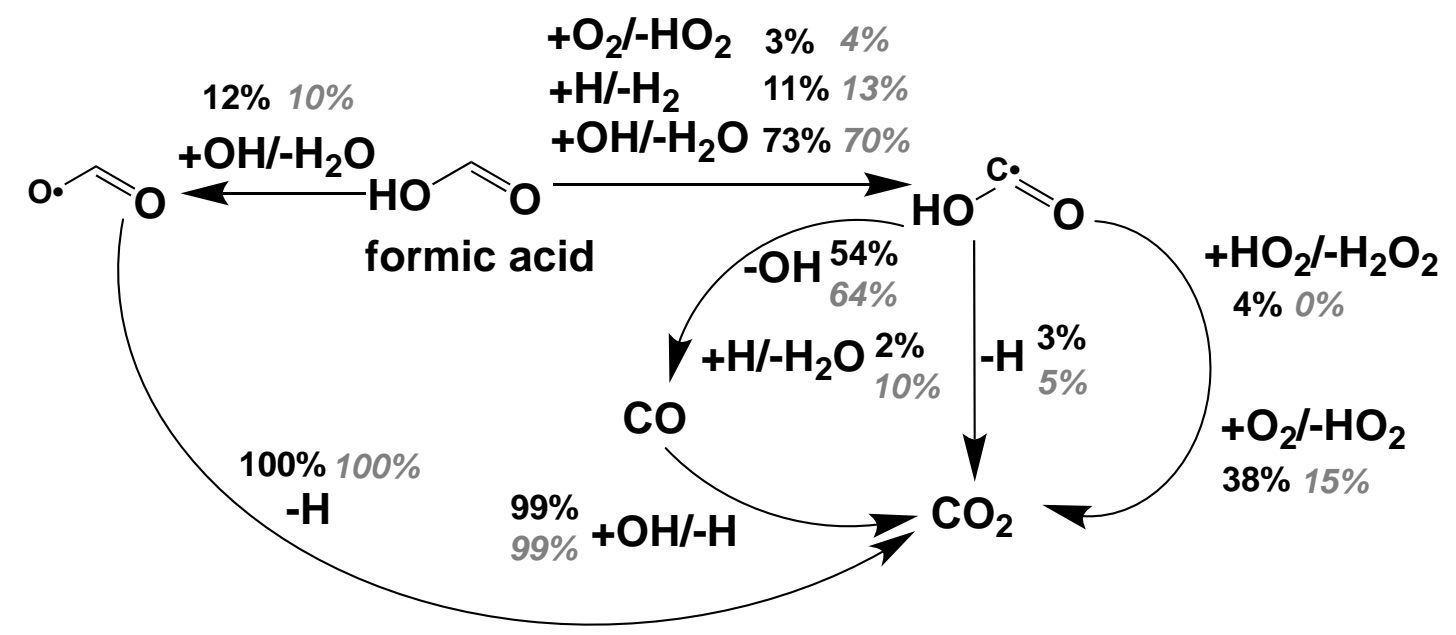

Figure 5 - Rate of consumption flux analysis for formic acid at $373 \mathrm{~K}, 1$ bar, stoichiometric conditions, and position corresponding to $75 \%$ of fuel consumed. Black text denotes percentage flux for HOCHO/air mixtures, while gray italicized text corresponds to $25 \% \mathrm{HOCHO} / 37.5 \% \mathrm{H}_{2} / 37.5 \% \mathrm{CO}_{2}$ / air mixtures.
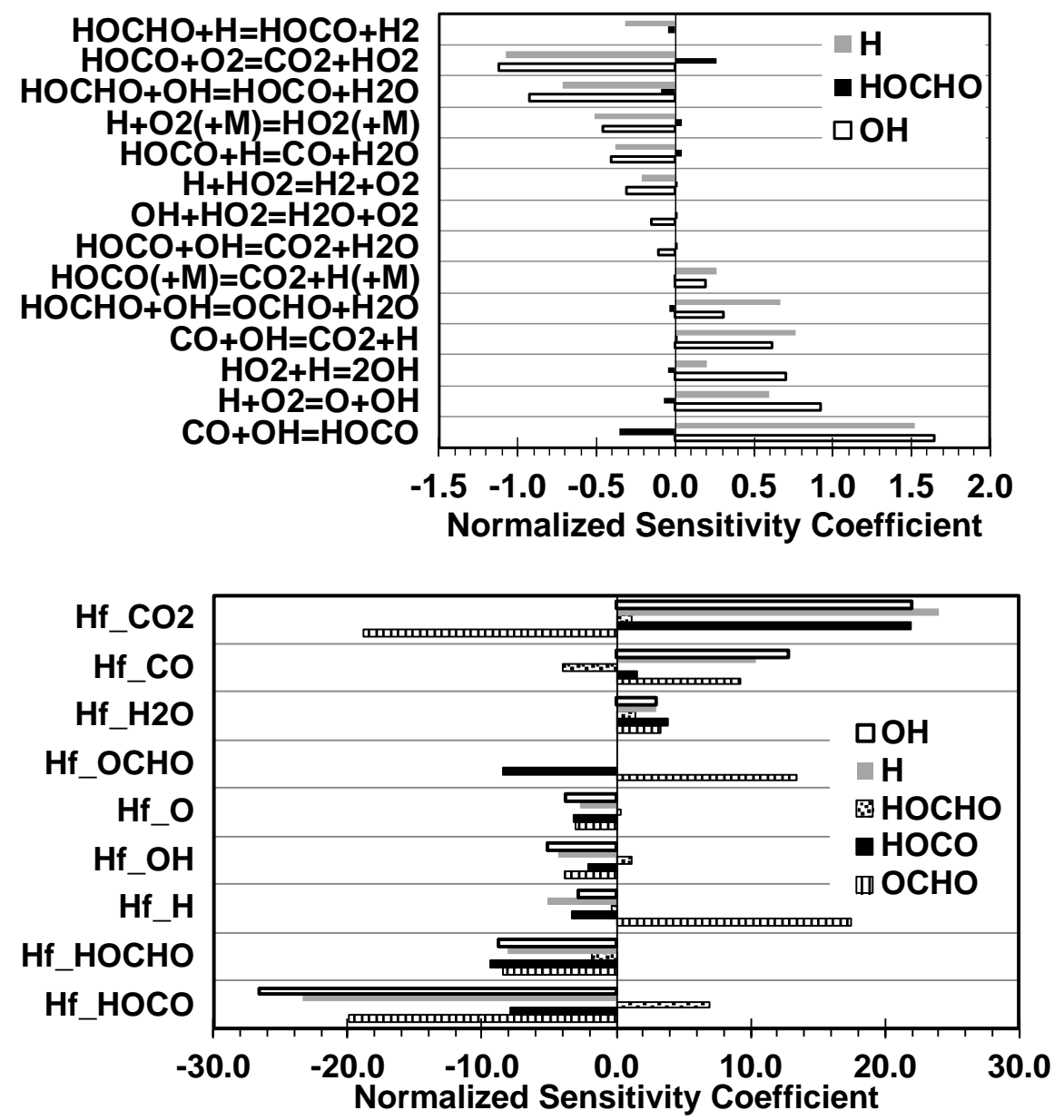
Figure 6 - Reaction (top) and species heat of formation (bottom) sensitivity analysis for HOCHO/air mixtures at $373 \mathrm{~K}$, 1 bar, stoichiometric conditions, and position corresponding to $75 \%$ of fuel consumed. Only top 14 and 9 common sensitive reactions (left) and species heat of formations (right), respectively, are shown.

\section{Conclusions}

The combustion of formic acid and its mixtures with hydrogen and carbon dioxide in laminar premixed flames was studied across a range of conditions to obtain laminar burning velocities and Markstein lengths. Experimental results showed that formic acid/air mixture show significantly lower burning velocities compared to typical hydrocarbon/air mixtures. Formic acid can be readily decomposed to produce $\mathrm{H}_{2}$ and $\mathrm{CO}_{2}$, and experiments showed that $\mathrm{H}_{2}$ addition could significantly increase burning velocities. As little as $32.5 \% \mathrm{H}_{2}$ addition (with equal parts of $\mathrm{CO}_{2}$ ) to formic acid can achieve burning velocities similar to those of methane/air mixtures, thereby making the mixtures suitable as engine fuel. Different trends in Markstein lengths versus equivalence ratio for formic acid and formic acid/ $\mathrm{H}_{2}$ mixtures were observed, and these could be attributed to well-known mechanisms of hydrogen response to stretch.

A modified detailed kinetic model was presented to predict laminar burning velocities by combining high fidelity kinetic models for formic acid and small hydrocarbon fuels. The proposed model is able to reproduce burning velocities for formic acid/air mixtures and blends containing $\mathrm{H}_{2}$ and $\mathrm{CO}_{2}$, albeit some discrepancies were observed. Reaction path analysis showed the importance of the HOCO radical intermediate in formic acid combustion, which decomposes to $\mathrm{CO}$ and $\mathrm{OH} ; \mathrm{CO}$ then oxidizes to $\mathrm{CO}_{2}$. Adding $\mathrm{H}_{2}$ to formic acid accelerates burning velocity by creating more $\mathrm{H}$ radicals that improve conversion of HOCO radical to CO. Sensitivity analysis showed the importance of HOCO related reactions in governing flame structure, as well as the enthalpy of formation of HOCO radicals on controlling the small radical pool. 
This study provides a foundation for future experimental and kinetic modeling studies on combustion of formic acid and its mixtures with $\mathrm{H}_{2}$ and $\mathrm{CO}_{2}$. The proposed kinetic model should be compared against other experimental data, such as ignition delay times and products species distribution, in order to refine the thermochemical and kinetic parameters. The research findings presented in this work can help in the design of engines and turbines operating on formic acid and its mixtures with hydrogen.

\section{Acknowledgments}

Research performed by the Clean Combustion Research Center was supported by King Abdullah Univeristy of Science and Technology (KAUST) and Saudi Aramco.

\section{References}

[1] S.Y. Leong, S.R.M. Kutty, A. Malakahmad, C.K. Tan, Feasibility study of biodiesel production using lipids of Hermetia illucens larva fed with organic waste, Waste Manag. 47 (2016) 84-90

[2] J. Eppinger, K.-W. Huang, Formic Acid as a Hydrogen Energy Carrier, ACS Energy Lett. 2 (1) (2017) 188-95

[3] K. Sordakis, C. Tang, L.K. Vogt, H. Junge, P.J. Dyson, M. Beller, et al., Homogeneous Catalysis for Sustainable Hydrogen Storage in Formic Acid and Alcohols, Chem. Rev. 118 (2) (2018) 372433

[4] X. Wang, Q. Meng, L. Gao, Z. Jin, J. Ge, C. Liu, et al., Recent progress in hydrogen production from formic acid decomposition, Int. J. Hydrogen Energy 43 (14) (2018) 7055-71

[5] J. Warnatz, U. Maas, R.W. Dibble, Combustion: Physical and chemical fundamentals, modeling and simulation, experiments, pollutant formation, 4th Ed., Springer Berlin Heidelberg, 2006, p. 1378 
[6] E. de Wilde, A. van Tiggelen, Burning Velocities in Mixtures of Methyl Alcohol, Formaldehyde or Formic Acid with Oxygen, Bull. Soc. Chim. Belges 77 (1968) 67-76

[7] P.G. Blake, H.H. Davies, G.E. Jackson, Dehydration mechanisms in the thermal decomposition of gaseous formic acid, J. Chem. Soc. B Phys. Org. (0) (1971) 1923-5

[8] D.S.Y. Hsu, W.M. Shaub, M. Blackburn, M.C. Lin, Thermal decomposition of formic acid at high temperatures in shock waves, Symp. Combust. 19 (1) (1982) 89-96

[9] K. Saito, T. Kakumoto, H. Kuroda, S. Torii, A. Imamura, Thermal unimolecular decomposition of formic acid, J. Chem. Phys. 80 (10) (1984) 4989-96

[10] K. Saito, T. Shiose, O. Takahashi, Y. Hidaka, F. Aiba, K. Tabayashi, Unimolecular Decomposition of Formic Acid in the Gas PhaseOn the Ratio of the Competing Reaction Channels, J. Phys. Chem. A 109 (24) (2005) 5352-7

[11] M. Klatt, M. Röhrig, H.G. Wagner, About the radical formation in the pyrolysis of formic acid at high temperatures, Zeitschrift für Naturforsch. 47 (11) (1992) 1138-40

[12] P. Marshall, P. Glarborg, Ab initio and kinetic modeling studies of formic acid oxidation, Proc. Combust. Inst. 35 (1) (2015) 153-60

[13] P. Brequigny, G. Dayma, F. Halter, C. Mounaïm-Rousselle, T. Dubois, P. Dagaut, Laminar burning velocities of premixed nitromethane/air flames: An experimental and kinetic modeling study, Proc. Combust. Inst. 35 (1) (2014) 703-10

[14] O. Mannaa, M.S. Mansour, W.L. Roberts, S.H. Chung, Laminar burning velocities at elevated pressures for gasoline and gasoline surrogates associated with RON, Combust. Flame 162 (6) (2015) 2311-21

[15] B. Galmiche, F. Halter, F. Foucher, Effects of high pressure, high temperature and dilution on laminar burning velocities and Markstein lengths of iso-octane/air mixtures, Combust. Flame 159 (11) (2012) 3286-99

[16] D. Bradley, P.H. Gaskell, X.J. Gu, Burning velocities, markstein lengths, and flame quenching for 
spherical methane-air flames: A computational study, Combust. Flame 104 (1-2) (1996) 176-98

[17] B. Galmiche, Caractérisation expérimentale des flammes laminaires et turbulentes en expansion PhD Thesis, Université d'Orléans, 2014,

[18] M.P. Burke, Z. Chen, Y. Ju, F.L. Dryer, Effect of cylindrical confinement on the determination of laminar flame speeds using outwardly propagating flames, Combust. Flame 156 (4) (2009) 771-9

[19] A.P. Kelley, C.K. Law, Nonlinear effects in the extraction of laminar flame speeds from expanding spherical flames, Combust. Flame 156 (9) (2009) 1844-51

[20] F. Halter, T. Tahtouh, C. Mounaïm-Rousselle, Nonlinear effects of stretch on the flame front propagation, Combust. Flame 157 (10) (2010) 1825-32

[21] R.J.K. A.E. Lutz, F.M. Rupley, Equil: A Chemkin Implementation of Stanjan for Computing Chemical Equilibria, Sandia National Laboratories Livermore, CA 94551, 1992 ,

[22] C. Lhuillier, P. Brequigny, N. Lamoureux, F. Contino, C. Mounaïm-Rousselle, Experimental investigation on laminar burning velocities of ammonia/hydrogen/air mixtures at elevated temperatures, Fuel (2019) 116653

[23] H. Yu, W. Han, J. Santner, X. Gou, C.H. Sohn, Y. Ju, et al., Radiation-induced uncertainty in laminar flame speed measured from propagating spherical flames, Combust. Flame 161 (11) (2014) 2815-24

[24] U. Burke, W.K. Metcalfe, S.M. Burke, K.A. Heufer, P. Dagaut, H.J. Curran, A detailed chemical kinetic modeling, ignition delay time and jet-stirred reactor study of methanol oxidation, Combust. Flame 165 (2016) 125-36

[25] S.M. Burke, W. Metcalfe, O. Herbinet, F. Battin-Leclerc, F.M. Haas, J. Santner, et al., An experimental and modeling study of propene oxidation. Part 1: Speciation measurements in jetstirred and flow reactors, Combust. Flame 161 (11) (2014) 2765-84

[26] A. Kéromnès, W.K. Metcalfe, K.A. Heufer, N. Donohoe, A.K. Das, C.-J. Sung, et al., An experimental and detailed chemical kinetic modeling study of hydrogen and syngas mixture 
oxidation at elevated pressures, Combust. Flame 160 (6) (2013) 995-1011

[27] S.M. Burke, U. Burke, R. Mc Donagh, O. Mathieu, I. Osorio, C. Keesee, et al., An experimental and modeling study of propene oxidation. Part 2: Ignition delay time and flame speed measurements, Combust. Flame 162 (2) (2015) 296-314

[28] W.K. Metcalfe, S.M. Burke, S.S. Ahmed, H.J. Curran, A Hierarchical and Comparative Kinetic Modeling Study of C1 - C2 Hydrocarbon and Oxygenated Fuels, Int. J. Chem. Kinet. 45 (10) (2013) 638-75

[29] A. Burcat, B. Ruscic, Third millenium ideal gas and condensed phase thermochemical database for combustion (with update from active thermochemical tables)., Argonne National Lab.(ANL), Argonne, IL (United States), Technion - Israel Inst. of Tech2005

[30] W.M.F. Fabian, R. Janoschek, Thermochemical properties of the hydroxy-formyl radical, HO$\mathrm{CO}$, and the formyloxy radical, $\mathrm{HC}(\mathrm{O}) \mathrm{O}$, and their role in the reaction $\mathrm{OH}+\mathrm{CO} \rightarrow \mathrm{H}+\mathrm{CO} 2$. Computational G3MP2B3 and CCSD(T)-CBS studies, J. Mol. Struct. THEOCHEM 713 (1-3) (2005) 227-34

[31] C.S. Mørch, A. Bjerre, M.P. Gøttrup, S.C. Sorenson, J. Schramm, Ammonia/hydrogen mixtures in an SI-engine: Engine performance and analysis of a proposed fuel system, Fuel 90 (2) (2011) $854-64$

[32] A. Ichikawa, A. Hayakawa, Y. Kitagawa, K.D. Kunkuma Amila Somarathne, T. Kudo, H. Kobayashi, Laminar burning velocity and Markstein length of ammonia/hydrogen/air premixed flames at elevated pressures, Int. J. Hydrogen Energy 40 (30) (2015) 9570-8

[33] C. Xia, P. Zhu, Q. Jiang, Y. Pan, W. Liang, E. Stavitsk, et al., Continuous production of pure liquid fuel solutions via electrocatalytic $\mathrm{CO} 2$ reduction using solid-electrolyte devices, Nat. Energy 4 (9) (2019) 776-85

[34] F. Wu, W. Liang, Z. Chen, Y. Ju, C.K. Law, Uncertainty in stretch extrapolation of laminar flame speed from expanding spherical flames, Proc. Combust. Inst. 35 (1) (2015) 663-70 
[35] P. Brequigny, F. Halter, C. Mounaïm-Rousselle, T. Dubois, Fuel performances in Spark-Ignition (SI) engines: Impact of flame stretch, Combust. Flame 166 (2016) 98-112

[36] D. Bradley, M. Lawes, R. Mumby, Burning velocity and Markstein length blending laws for methane/air and hydrogen/air blends, Fuel 187 (2017) 268-75

[37] T. Tahtouh, F. Halter, E. Samson, C. Mounaïm-Rousselle, Effects of hydrogen addition and nitrogen dilution on the laminar flame characteristics of premixed methane-air flames, Int. J. Hydrogen Energy 34 (19) (2009) 8329-38

[38] T. Tahtouh, F. Halter, C. Mounaïm-Rousselle, Laminar premixed flame characteristics of hydrogen blended iso-octane-air-nitrogen mixtures, Int. J. Hydrogen Energy 36 (1) (2011) 98591 
